Full length article

Special Issue Biosensors 2008

\title{
Revisited BIA-MS combination: Entire “on-a-chip” processing leading to the proteins identification at low femtomole to sub-femtomole levels

\author{
W. Boireau ${ }^{1 *}$, A. Rouleau ${ }^{1}$, G. Lucchi ${ }^{2}$, P. Ducoroy ${ }^{2}$
}

${ }^{1}$ Institut FEMTO-ST, Université de Franche Comté, Clinical-Innovation Proteomic Platform, CNRS 25044 Besançon, France

${ }^{2}$ Clinical-Innovation Proteomic Platform, Université de Bourgogne / CHU - 8 Boulevard Maréchal de Lattre de Tassigny - 21000 Dijon, France

*Corresponding Author: Wilfrid Boireau, e-mail : wboireau@,femto-st.fr

\begin{abstract}
We present the results of a study in which biomolecular interaction analysis (BIA, Biacore ${ }^{\mathrm{TM}}$ 2000) was combined with Mass Spectrometry using entire "on-a-chip" procedure. Most BIA-MS studies included an elution step of the analyte prior MS analysis. Here, we report a low-cost approach combining Biacore analysis with homemade chips and MS in situ identification onto the chips without elution step. First experiments have been made with Rat Serum Albumin to determine the sensitivity and validation of the concept has been obtained with an antibody/antigen couple. Our "on-a-chip" procedure allowed complete analysis by mass spectrometry $\left(\mathrm{MS} / \mathrm{MS}^{2}\right)$ of the biochip leading to protein identifications at low femtomole to sub-femtomole levels. Using this technique, identification of protein complexes were routinely obtained giving the opportunity to the "on-a-chip" processing to complete the BIA-MS approach in the discovery and analysis of protein complexes.
\end{abstract}

\section{Keywords}

BIA-MS, SPR, MALDI-TOF, SAM, protein complexes 


\section{Introduction}

Many cutting-edge technologies are available in proteomics but the combination of two or more technologies will help overcome major drawbacks in analytical methods. Some of these combinations such as liquid chromatography (LC) with mass spectrometry (MS) giving LC-MS and LC-MS-MS approaches are used routinely today. Recently, new methods combining biosensors with MS have been explored. Out scope of passive surface which provided no information on the biological events that occur at the surface of the chip, the last decade has seen an increasing interest in intelligent surfaces mainly based on surface plasmon resonance (SPR) which allow monitoring of biorecognitions and captures in real time without any labeling (Nilsson et al, 1995; Nieba et al, 1997; Frederix et al., 2003, Grosjean et al, 2005). Few groups have developed the combination of SPR devices with mass spectrometry leading to a new concept called BIA-MS for Biomolecular Interaction Analysis-Mass Spectrometry (Natsume et al., 2000; Nedelkov and Nelson, 2000; Lopez et al., 2003; Catimel et al., 2005; Larsericsdotter et al., 2006, Bouffartigues et al., 2007). Briefly, this combination of instruments has led to better global proteomic analysis by combining qualitative (kinetics of interactions) and quantitative (amount of bound proteins) information provided by SPR with the structural features of the proteins thanks to mass spectrometry. The first step of this analytical method provides intact proteins immobilized on a chip. The proteins can then be analyzed further using MS, either directly on the chip or after an elution step. The main approach deals with elution of bound materials which slow down the sensitivity. In order to overcome major drawbacks of this elution way (rate of eluted protein of interest, dilution of the sample, loss of materials and incompatibility between the elution buffer used and the mass spectrometry, reproducibility...), very few studies have explored direct digestion of the immobilized proteins, which are in situ analyzed using MS after SPR experiments (Grote et al., 2005). From our knowledge, this approach has not been yet successfully explored and some drawbacks must be overcome as the conception and realization of low cost SPR chips, the optimization of pre-treatments prior to mass spectrometry analysis, the global sensitivity of this approach. So, if the combination of SPR with MS has great potential in functional proteomics, the association of two techniques still presents a challenge (Buijs and Franklin, 2005). 
In this paper, we described an efficient "off-line" method leading to an optimize combination of Surface Plasmon Resonance experiments with mass spectrometry analysis on the same chip. Biological models are Rat Serum Albumin (RSA) for the establishment of the procedure and sensitivity optimization and LAG-3 protein, a specific marker of human breast cancer and tuberculosis for validation of this approach for the characterization and identification of protein complexes (Triebel et al., 2006). Our developments consisted in the conception and the realization of home-made protein chips compatible with SPR analysis. Then we presented complete on-a-chip treatments prior to mass spectrometry analysis with a home-made MALDI plate. Finally, all the proteins were completely identify by peptide mass fingerprints (PMF) and MS-MS analysis at the sub-femtomole to femtomole levels.

\section{Materials and methods}

\subsection{Reagents}

Rat Serum Albumine, DiThioThreitol (DTT) NH4HCO3, Acetonitrile, TriFluoroAcetic acid (TFA) were obtained from Sigma-Aldrich. HCCA Matrix was from Bruker Daltonics (Bremen, Germany). Absolute ethanol was from Carlo Erba. HBS buffer was purchased from Biacore (GE Healthcare). Ultrapure water was produced with an Elga Instrument.

\subsection{Design and fabrication of homemade chips}

First, a $2 \mathrm{~nm}$ thick chromium $\left(\mathrm{Cr}\right.$ ) layer was deposited on a $\mathrm{SiO}_{2}$ wafer (width: $13 \mathrm{~mm}$, thickness: 0.17 mm from AGAR) with plasma sputtering technology to optimize the adherence of gold to the substrate. The $40 \mathrm{~nm}$ thick Au layer was deposited onto the top of the Cr layer using plasma sputtering technology. The deposition time and the argon flow pressure were optimized to obtain the theoretical thickness. The deposition time for the $\mathrm{Cr}$ and $\mathrm{Au}$ layers were respectively 3 and $22 \mathrm{sec}$. For all depositions, the argon flow pressure and current were respectively $7 \mu$ bar and $0.3 \mathrm{~A}$. With these parameters, the deposition rates for the $\mathrm{Au}$ and $\mathrm{Cr}$ layers were respectively 109 and $60 \mathrm{~nm} / \mathrm{min}$.

\subsection{Chemical functionalization \& SPR experiments}


The homemade chips were chemically functionalized as follows:

For the RSA chip, a solution of Octadecyl Mercaptan (OM), $1 \mathrm{mM}$ in an ethanol/water solution (4/1 by vol.), was sonicated for 20 minutes using Elma, (Power90W, frequency 50/60 Hz) at maximal power. The sensor chips were cleaned in baths of absolute ethanol then treated overnight and rinsed with ultra pure ethanol and water. Ultrapure water contact angles were measured with a goniometer system (DIGIDROP by GBX, France) with an accuracy of $+/-2^{\circ}$. All measurements were performed in the ambient atmosphere at room temperature.

For the immuno-chip, we used a self assembled monolayer composed of a mixture of 11-mercapto-1undecanol (11-MUOH) and 16-mercapto-1-hexadecanoic acid (16-MHA) (purchased from SigmaAldrich). The mixture of $11-\mathrm{MUOH} / 16-\mathrm{MHA}$ ( $97 / 3$ by mole) at $1 \mathrm{mM}$ in absolute ethanol was sonicated $10 \mathrm{~min}$ using a sonicator Elma (Power 90W, frequency $50 / 60 \mathrm{~Hz}$ ). LAG-3 protein is provided by Immutep SA (Châtenay Malabry, France) and is known as a prognostic indicator for survival of primary breast carcinomas. Monoclonal antibody A9H12 recognize specifically LAG-3 protein and dimeric LAG-3 recombinant protein used for this study. Their molecular masses are $160 \mathrm{kDa}$ both.

BIAcore experiments were performed with the Biacore ${ }^{\mathrm{TM}} 2000$ apparatus at $25{ }^{\circ} \mathrm{C}$ with a flow rate comprise between 2 and $30 \mu \mathrm{l} / \mathrm{min}$. According to the experiments, the running buffer was either ultrapure water (Rathburn), saline phosphate buffer (PBS, 100mM at pH7.4 with $\mathrm{NaCl} 50 \mathrm{mM}$ ) or $\mathrm{HBS}$ buffer. The degree of protein immobilization and the level of interactions in the Biacore technology apparatus were plotted on a sensorgram (response unit (RU) versus time (s)). One thousand RU correspond to a shift in the resonance angle of $0.1^{\circ}$. Calibration of the apparatus gives a correlation between the shift in angle and the mass, ranging from 0.1 to $1 \mathrm{ng} / \mathrm{mm}^{2}$, deposition on the surface of the biochip (Stenberg et al., 1991). After exposure to the analytical solution, the chips were then removed from the Biosensor unit via undock procedure with empty flow cell command.

\subsection{On-Chip Digestion}

To identify the bound protein on the sensor chip, the proteins were reduced with DTT (10 min) and digested with trypsin. On-target tryptic digestion was performed by depositing $1 \mu \mathrm{L}$ of $5 \mu \mathrm{g} / \mathrm{mL}$ trypsin 
(Trypsin Gold Mass Spectrometry Grade, PROMEGA), dissolved in 100mM NH4HCO3, pH 8.2, onto selected sample spots. During digestion, water was added and the chip was kept at $37^{\circ} \mathrm{C}$ for $10 \mathrm{~min}$ according to Terry's procedure (Terry et al., 2004). After digestion, the spots were dried and $1 \mu \mathrm{L}$ saturated HCCA in $30 \%$ acetonitrile/ $0.1 \%$ TFA was added to each spot using a pipette for RSA analysis and the matrix was not saturated $(3,5 \mathrm{mg} / \mathrm{ml})$ in $50 \%$ acetonitrile/TFA $0,1 \%$ in the case of protein complexes. To calibrate the mass spectrometer, standard peptides (pepmix standard peptide from Bruker Daltonics) were deposited onto the sample spots of the chip. The global pre-treatment is no longer than 30 min which warrants an entire BIA-MS study in few hours.

\subsection{MALDI- TOF Mass Spectrometry}

The chips were then introduced in a mass spectrometer MALDI-TOF (Ultraflex, Bruker Daltonics Gmhb, Bremen, Germany), using a home made MALDI target. Ionisation was performed in MS and MS/MS (PDS-LIFT technology) by irradiation of a nitrogen laser $(337 \mathrm{~nm}$ ) operating at $50 \mathrm{~Hz}$. Data were acquired at a maximum accelerating potential of $25 \mathrm{kV}$ in the positive and reflectron modes. The MALDI mass spectra were calibrated using the Peptide Calibration Standards from Bruker Daltonics. The software packages Ultraflex version 3.0, Flex control, Flex Analysis and Biotools version 3.1 were used to record and analyze the mass spectra. The database search was performed with Mascot (Matrix Science, London, U.K.) in the NCBI database. Peptide tolerance was set at $\pm 50 \mathrm{ppm}$ in MS and $\pm 0.4 \mathrm{Da}$ in MS/MS. Methionine oxidation was accepted as a variable modification.

\section{Results- Discussion}

\subsection{Proof of concept of entire "on-a-chip" BIA-MS analysis of RSA at sub-femtomole per mm²}

Crude gold chips were chemically functionalized with octadecyl mercaptan in order to confer the same properties than the HPA sensorchip ${ }^{\circledR}$ (provided by Biacore). The self-assembled monolayer (SAM) process, obtained using a previously published procedure (Boireau et al., 2002), leads to the formation of a packed monolayer of OM, which confers a high degree of hydrophobicity to the chip (Fig. 1A). This was confirmed using contact angle measurements as summarized in Figure 1B, the average angle formed by small water drops onto the SAM reached $107^{\circ}+/-2^{\circ}$, which is close to the value expected 
for such a substrate (Kawasaki et al., 2000). Hydrophobicity is the driving force which allows the adsorption of a large number of biological compounds (proteins, nucleic acids, lipids...). In our study, the OM layer was used as hydrophobic matrix to adsorb RSA. The adsorption process was followed in real time by surface plasmon resonance measurements. Briefly, the functionalized homemade chip was inserted into the Biacore apparatus: the response in water at $25^{\circ} \mathrm{c}$ and $30 \mu 1 / \mathrm{min}$ was measured. In order to prepare the surface for adsorption process, it was cleaned with a pulse of organic solvent, ethanol ( $50 \%$ in water), followed by a pulse of detergent, OG $(40 \mathrm{mM})$. Following this procedure (i) various concentrations of RSA were injected onto the chip, (ii) the level of adsorption in real time was measured and (iii) the injection was stopped when the signal reached the expected values. The sensorgrams of the experiment are presented in Figures 1C, D. At high concentrations of RSA (i.e. above $1 \mathrm{mg} / \mathrm{ml}$ ) the kinetics of monolayer assembly were quick and followed by a plateau (BlondeauPatissier et al., 2007). The resulting protein monolayer was stable leading to an average of $1250+/-$ 250 RU i.e. 19 femtomole $/ \mathrm{mm}^{2}$ (Fig. 1C). It was possible to monitor the surface coverage of the RSA by reducing its concentration and the time of injection. That way only a small amount of RSA can be adsorbed and detected (theoretically up to the detection limit of the BIAcore apparatus i.e. about 0.1 femtomole $/ \mathrm{mm}^{2}$ ). We have performed many experiments of immobilization at low concentration leading to a range of surface coverage comprised between 0.7 and 5 femtomoles of RSA per $\mathrm{mm}^{2}$. An illustration of such experiment is given in Figure 1D where the adsorption kinetics of RSA is monitored at $0.1 \mathrm{mg} / \mathrm{ml}$ for $100 \mathrm{sec}$ of injection and has lead to a surface coverage of 2 femtomoles $/ \mathrm{mm}^{2}$. At the end of the injection, the chip was then removed from the Biacore unit via the "undock" procedure with "empty flow cell" command and the gold chips are removed from the plastic support.

To identify by mass spectrometry the RSA on the sensor chip, the adsorbed material was reduced and alkylated (see material and methods). On-target tryptic digestion was performed by depositing 100 femtomoles of trypsin onto selected sample spots. During digestion, water was added and the chip was kept at $37^{\circ} \mathrm{C}$ for $10 \mathrm{~min}$. After digestion, the spots were dried and HCCA matrix was added to each spot using a pipette. To calibrate the mass spectrometer, standard were deposited onto the sample spots of the chip. After in situ treatment of the sample, the chip is placed into a modified MALDI 
target before being analyzed in the mass spectrometer. MALDI targets were modified in order to receive the chip and maintain a regular target surface. The chips were fixed with conducting sticking tape because MALDI targets must provide an electrically conductive surface. These two points guaranty good sensitivity and reproducibility for ionization over the surface of the chip and prevent electric arcs between the target and the first lens.

Figure 2 shows MALDI-TOF mass spectra resulting from the treatment and analysis of 0.7 femtomole $/ \mathrm{mm}^{2}$ of RSA captured and treated directly on the chip as previously described. The most intense peaks corresponded to the peptides generated by self-digestion of the trypsin. These trypsin auto-hydrolysis peaks were used for internal calibration of the spectra. In spite of the very low density of molecules of RSA present on the chip, the treatment is highly efficient in a short time (less than 1 hour) and presented a rich peptide profile. Thus, twenty-three (23) peptides matched the sequence of RSA in submitting to the Mascot search engine. The database query allowed us to identify RSA with a significant score in MASCOT (Digest Matches, Score: 198). Moreover, the sequence coverage represented by these peptides for this protein was $36 \%$ enabling its highly reproducible identification by peptide mass fingerprinting at low to sub-femtomole levels.

\subsection{Validation of entire "on-a-chip” BIA-MS analysis at femtomole $/ \mathrm{mm}^{2}$ level of Ab/Ag couple and their identification by MS and MS/MS analysis.}

We validated this procedure with a relevant biological model (courteously provided by Immutep SA, France) composed of an antibody (IgG1:A9H12) which recognize specifically the LAG3 protein a specific biomarker of human diseases (breast cancer and tuberculosis). In order to immobilize A9H12, we functionalized gold surface with a mixture of 11-mercapto-1-undecanol (11-MUOH) and 16mercapto-1-hexadecanoic acid (16-MHA). A scheme of the immunosensor is presented in Figure 3A. Briefly, the resulted self assembled monolayer presents small amount ( $3 \%$ by mole) of 16-MHA molecule which bears one carboxyl group. These groups were activated using N-hydroxysuccinimide (NHS) and N-(3-dimethylaminopropyl)-N-ethylcarbodiimide (EDC). Immobilization of A9H12 was mainly realized through primary amine group of lysine and the reconstitution of such immunosensor fit well with the Frederix's procedure (Frederix et al., 2003). At the end of the process, the inactivation 
of the chip was obtained with a pulse of ethanolamine and the quantification of the antibody grafting can be done. High control on the surfacic coverage was performed according to the time of injection and the concentration of $\mathrm{A} 9 \mathrm{H} 12$. Thus we are able to propose an antibody immobilization comprise between 1 and 10 femtomoles $/ \mathrm{mm}^{2}$. In Figure 3B, four injections of A9H12 (represented with an asterisk) give a SPR response about 1020 RU (i.e. $\approx 6.4$ femtomoles of A9H12 per $\mathrm{mm}^{2}$ ). We verified that the packed monolayer of antibody present high properties of biomolecular interactions with LAG3 antigen (Figure 3C). For concentration above $1 \mu \mathrm{M}$, we observed an equilibrium state leading to a surface density of LAG3 equivalent to the surface density in antibody $\left(\approx 6.1\right.$ femtomoles $/ \mathrm{mm}^{2}$, i.e. corresponding to one antigen per antibody). At this level of recognition, we stopped the SPR experiments and removed the chip from Biacore2000 apparatus through the "undock procedure".

The pre-treatment procedure prior to MS experiments was similar with the one established for RSA identification. At the end of the process, the chip was placed on MALDI plate in order to be analyzed and results in identifications were given in Figure 4. In spite of the presence of various proteins on the chip (Trypsin, A9H12 and modified LAG-3 protein), results of PMF lead to identification with high significance (Mascot score above 80 ) for both biological partners and were summarized in table 2 . We routinely obtained high score in identification of both antibody and antigen at a level of few femtomoles $/ \mathrm{mm}^{2}$. Thus, with this innovating and original method, we demonstrated the possibility of performing PMF identification of protein complexes in using exclusively an "on-a-chip" BIA-MS analysis.

Moreover, in the case of protein complexes, PMF could not allow complete identifications of each protein and tandem mass spectrometry (MS/MS) is broadly required. We have also explored this analytical pathway and demonstrated that each protein could be identified by MS/MS analysis. Many peptides from various proteins can be fragmented in each experiment (above 4 peptides per protein for more than 10 chips analyzed) leading to unambiguous identification of antibody and antigen species. The MS/MS analysis of peptide 1374 is shown in Figure 5 and gave unambiguous LAG-3 identification with significant Mascot score. So the rich peptide profile obtained (which could limit the accuracy of the analysis in the case of multiproteins complex) warrants a reservoir of peak analysable by tandem mass spectrometry. 
Some authors have argued that "on-a-chip" procedure could not be realistic for protein complexes characterization and identification and recommended in fact an elution strategy (Natsume et al. 2001, Buijs et al., 2005). From their opinion, "on-a-chip" BIA-MS presents some limitations in regard with the elution way which can be summarized as follow: "on-a-chip" approach is a destructive investigation and the chip cannot be reused (i) and was not adapted for protein (and protein complexes) identification because of the large number of peptide resulting from the tryptic digestion (ii). Our results have demonstrated that these drawbacks can be overcome:

(i) The destruction of the biochip during MS analysis is still actual but is strongly attenuated when the chips is produced at low cost (conception, realization and functionalization processes of the chips are performed in clean room and controlled laboratory environment with reduced costs).

(ii) The major drawback deals with the limitation of identification of protein complexes directly on the chip. This technique has been considered only helpful when the molecular mass of protein bound to the sensor chip is known or predicted. Most of their developments have been more purchased for protein detection than for protein identification (Nedelkov and Nelson, 2001, 2003). Recently, Treitz and co-workers have combined SAW-biosensor with MALDI-MS analysis through an "on-a-chip" approach (Treitz et al. 2008). However, in order to analyze deeply protein complexes on the chip, they performed nano-LC experiments prior to MALDI-MS at 750 femtomoles $/ \mathrm{mm}^{2}$. Grote and co-workers presented such experiments in deposing directly on their chip few picomoles of cytochrome C following by a tryptic digestion and PMF analysis (Grote et al., 2005). But in this case the chip is a passive substrate and is disconnected from the transduction signal. The "on-a-chip" MS analysis on digest of protein has been poorly investigated in the past. In this paper, we demonstrated the feasibility in protein complexes characterization and "off-line" identification at the femtomole $/ \mathrm{mm}^{2}$ level. From our knowledge, this work is the first complete coupling between SPR and MS with entire "on-thechip" analysis leading to identification of protein complexes. Our global approach (conception/realization of chips, (bio)-functionnalization of the gold surface, pre-treatments and MS analysis) offers a real alternative to the elution way with a similar levels of performance in sensitivity and accuracy. 
Recently Nedelkov has opened the way to the development of the first functional SPR-MS array platform (Nedelkov, 2007). These first results seem to be well suited for high-content protein microarrays and comprehensive protein analysis from quantitative assessment of the protein concentration to detection of structural protein. Our strategy could take benefit of this original development and could contribute to the complete automation of the protein identification and posttransciptional modifications analysis in high throughput applications.

\section{Conclusion}

We presented in this paper the developments of home-made gold biochips compatible both with the Biacore apparatus and with the targets of MALDI-MS instrument. These developments were based on the design, fabrication and functionalization of biochips compatible with Biacore experiments as well as the insertion of chips into MALDI targets that are compatible with the MALDI-MS instrument, the optimisation of "on-the-chip" sample digestion, and finally the optimization of acquisition parameters of MS spectra. For the first time, these developments and optimizations have made it possible to identify by MS and MS-MS proteins directly on the chip at femtomole and sub-femtomole levels without elution of bound materials. The global "on-a-chip" and "off-line" approach does not reduce the potential of the two methods taken independently. At contrary, this approach seems to be the simplest way to obtain quantitative and qualitative data for the analysis of protein complexes and seems to have a great potential for high throughput applications. In the near future, recent technological advances should enable us to continue our investigations into sensitivity and characterization of protein biomarkers captured in biological fluids.

\section{Acknowledgements}

The BIA-MS project is financially supported by the Regional Council of Burgundy, IFR-STIC-Santé, University of Dijon, CHU of Dijon and by a fellowship PPF "Microtechniques for Proteomic" from 
Ministère de l'Enseignement Supérieur et de la Recherche (MESR). We thank Thomas Mangeat and Céline Elie-Caille for the development of gold chips and the technologic platform MIMENTO, Frédéric Triebel (from Immutep SA.) for providing A9H12/LAG-3 model. 


\section{References:}

Blondeau-Patissier V, Boireau W, Cavallier B, Lengaigne G, Daniau W, Martin G, Ballandras S (2007) Sensors. 7, 1992-2003

Boireau W, Bombard S, Sari MA, Pompon D (2002) Biotechnol. Bioeng. 77, 225-231

Bouffartigues E, Leh H, Anger-Leroy M, Rimsky S, Buckle M (2007) Nucleic Acid Res. 35, e39

Buijs J, Franklin GC (2005) Briefings in Functional Genomics and Proteomics. 4, 39-47

Catimel B, Rothacker J, Catimel J, Faux M, Ross J, Connolly L, Clippingdale A, Burgess AW, Nice E (2005) J. Prot. Research. 4, 1646-1656

Frederix F, Bonroy K, Laureyn W, Reekmans G, Campitelli A, Dehaen W, Maes G (2003) Langmuir. $19(10), 4351-4357$

Grosjean L, Cherif B, Mercey E, Roget A, Levy Y, Marche PN, Villiers MB, Livache T (2005) Anal Biochem. 347, 193-200

Grote J, Dankbar N, Gedig E, Koenig S (2005) Anal. Chem. 77, 1157-1162

Kawasaki M, Sato T, Tanaka T, Takao K (2000) Langmuir. 16, 1719-1728

Larsericsdotter H, Jansson O, Zhukov A, Areskoug D, Oscarsson S, Buijs J (2006) Proteomics. 6, $2355-2364$

Lopez F, Pichereaux C, Burlet-Schiltz O, Pradayrol L, Monsarrat B, Estève JP (2003) Proteomics. 3, $402-412$

Natsume T, Nakayama H, Jansson S, Isobe T, Takio K, Mikoshiba K (2000) Anal. Chem. 72, 41934198

Natsume T, Nakayama H, Isobe T (2001) TIBS. 19, S28-S33

Nedelkov D, (2007) Anal. Chem. 79, 5987-5990

Nedelkov D, Nelson RW (2000) J. Mol. Recogn. 13, 140-145

Nedelkov D, Nelson RW (2001) Biosen. Bioelec. 16, 1071-1078 
Nedelkov D, Nelson RW (2003) Appl. Env. Microbiol. 69, 5212-5215

Nieba L, Nieba-Axmann S.E, Persson A, Hamalainen M, Edebratt F, Hansson A, Lidholm J, Magnusson K, Karlsson AF, Pluckthun A (1997) Anal. Biochem. 252 (2), 217-228

Nilsson P, Persson B, Uhlen M, Nygren PA (1995) Anal Biochem. 224, 400-408

Stenberg E, Persson B, Roos H, Urbaniczky C (1991) J. Colloid Interface Sci. 143, $513-526$

Terry DE, Umstot E, Desiderio DM (2004) J Am Soc Mass Spectrom 15, 784-794

Treitz G, Gronewold TMA, Quandt E, Zabe-Kühn M (2008) Biosen Bioelect. 23, 1496-1502

Triebel F, Hacene K, Pichon MF (2006) Cancer Lett. 235, 147-153 
Figure 1. SPR monitoring of RSA adsorption on OM layer.

(A) Molecular structure of self assembled monolayer of Octadecyl Mercaptan (OM) (B) Contact angle measurement of small drop of water deposited on OM (C) Sensorgram (Response in RU vs Time in S) of the adsorption of a highly packed monolayer of RSA $(1 \mathrm{mg} / \mathrm{ml})$ on OM $\left(1250 \mathrm{RU} \approx 1,25 \mathrm{ng} / \mathrm{mm}^{2}\right.$ i.e. $\left.19 \mathrm{fmoles} / \mathrm{mm}^{2}\right)$. (D) Sensorgram of the adsorption of low density of RSA $(0.1 \mathrm{mg} / \mathrm{ml})$ on OM $\left(130 \mathrm{RU} \approx 0.13 \mathrm{ng} / \mathrm{mm}^{2}\right.$ i.e. $\left.2 \mathrm{fmoles} / \mathrm{mm}^{2}\right)$.

Figure 2. Peptide mass fingerprint recorded for RSA at 700 amol after biosensor capture (RSA; accession number gi|19705431). The inset represents 23 peptides matched out of 48 masses submitted to the Mascot search engine.

Figure 3. SPR monitoring of A9H12 immobilization on activated SAM and LAG-3 capture.

(A) Scheme of the molecular structure of A9H12 immuno-chip (B) Sensorgram (Response in RU vs Time in S) of the immobilization of A9H12 on 11-MUOH/16-MHA (97/3 by mole) Self Assembled Monolayer $\left(1020 \mathrm{RU} \approx 1 \mathrm{ng} / \mathrm{mm}^{2}\right.$ i.e. 6 fmoles of A9H12 per $\left.\mathrm{mm}^{2}\right)$. (C) Sensorgram of the biorecognition of LAG-3 protein $\left(980 \mathrm{RU} \approx 1 \mathrm{ng} / \mathrm{mm}^{2}\right.$ i.e. $\left.6 \mathrm{fmoles} / \mathrm{mm}^{2}\right)$. Each injections are indicated with *.

Figure 4. Peptide mass fingerprint recorded for the couple A9H12/LAG3 at 6 femtomoles $/ \mathrm{mm}^{2}$ (IgG 2A; accession number gi|194438) and (LAG-3; accession number gi|106885). Peptide tolerance was sat at $+/-50$ ppm in MS analysis.

Figure 5: MS/MS analysis of fragment 1374 of LAG-3 protein with annotated b- and y-ions of analyzed peptide sequence RYTVLSVGPGGLR (identified residues are underlined). 
Figure 1
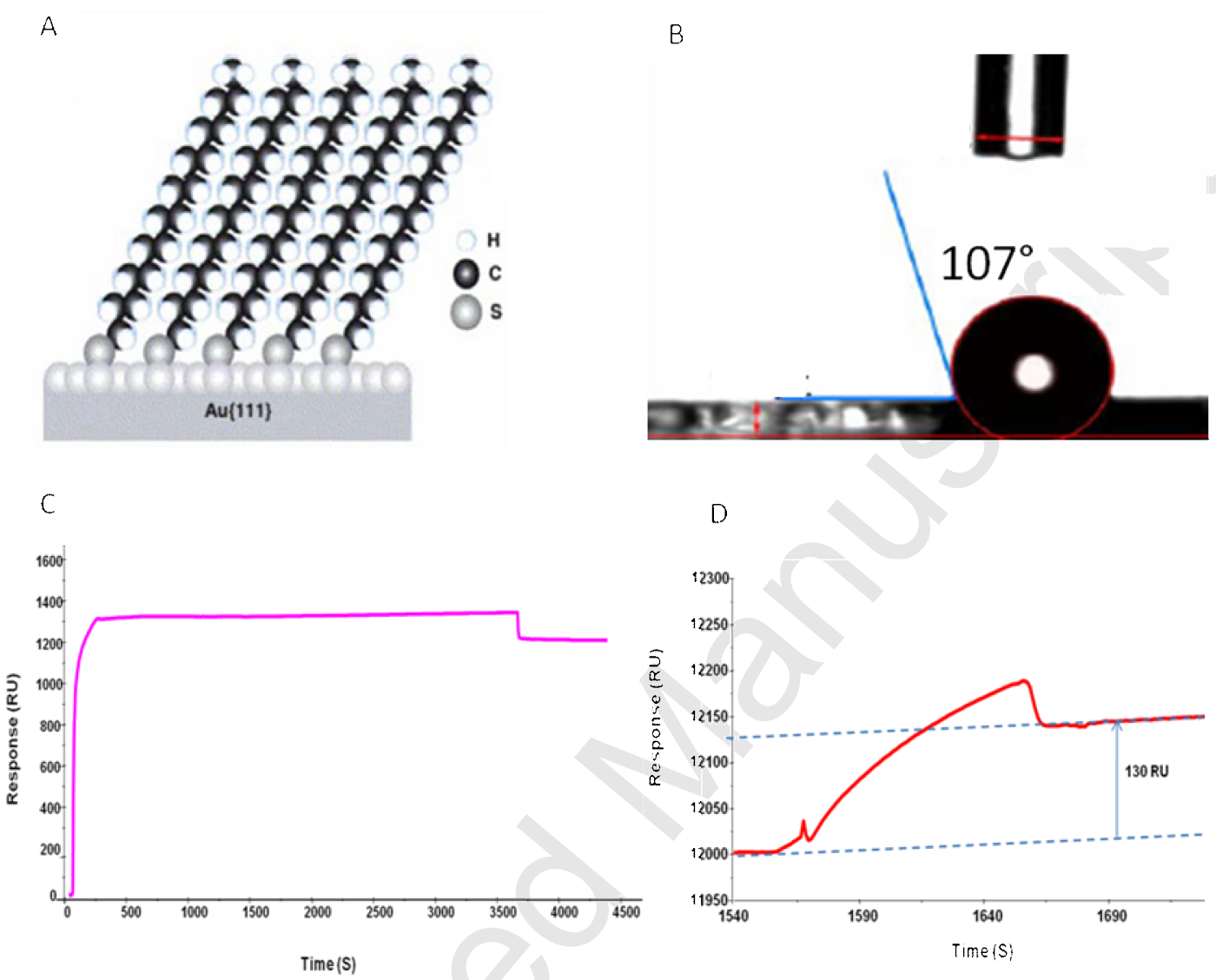
Figure 2

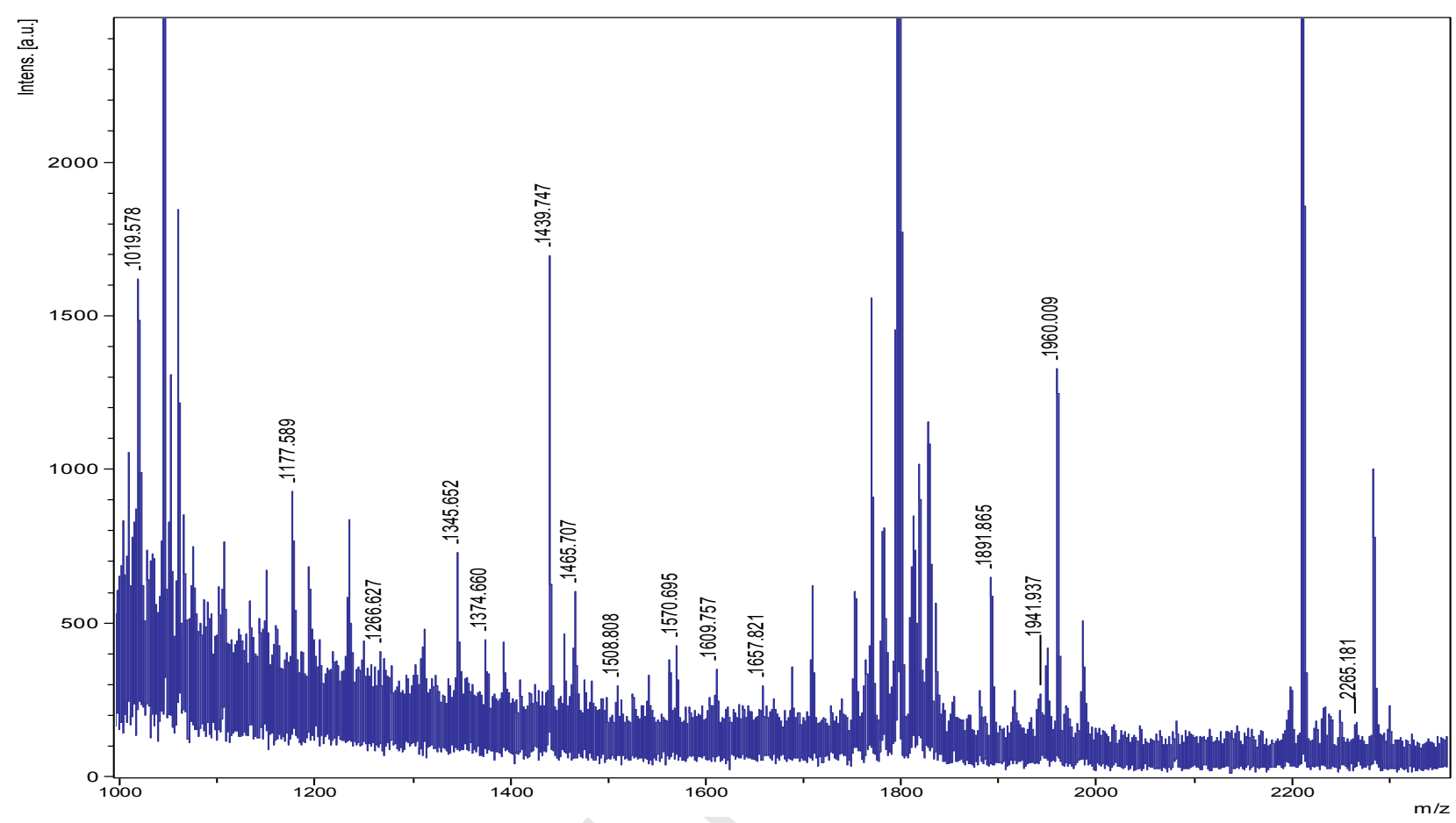


Figure 3
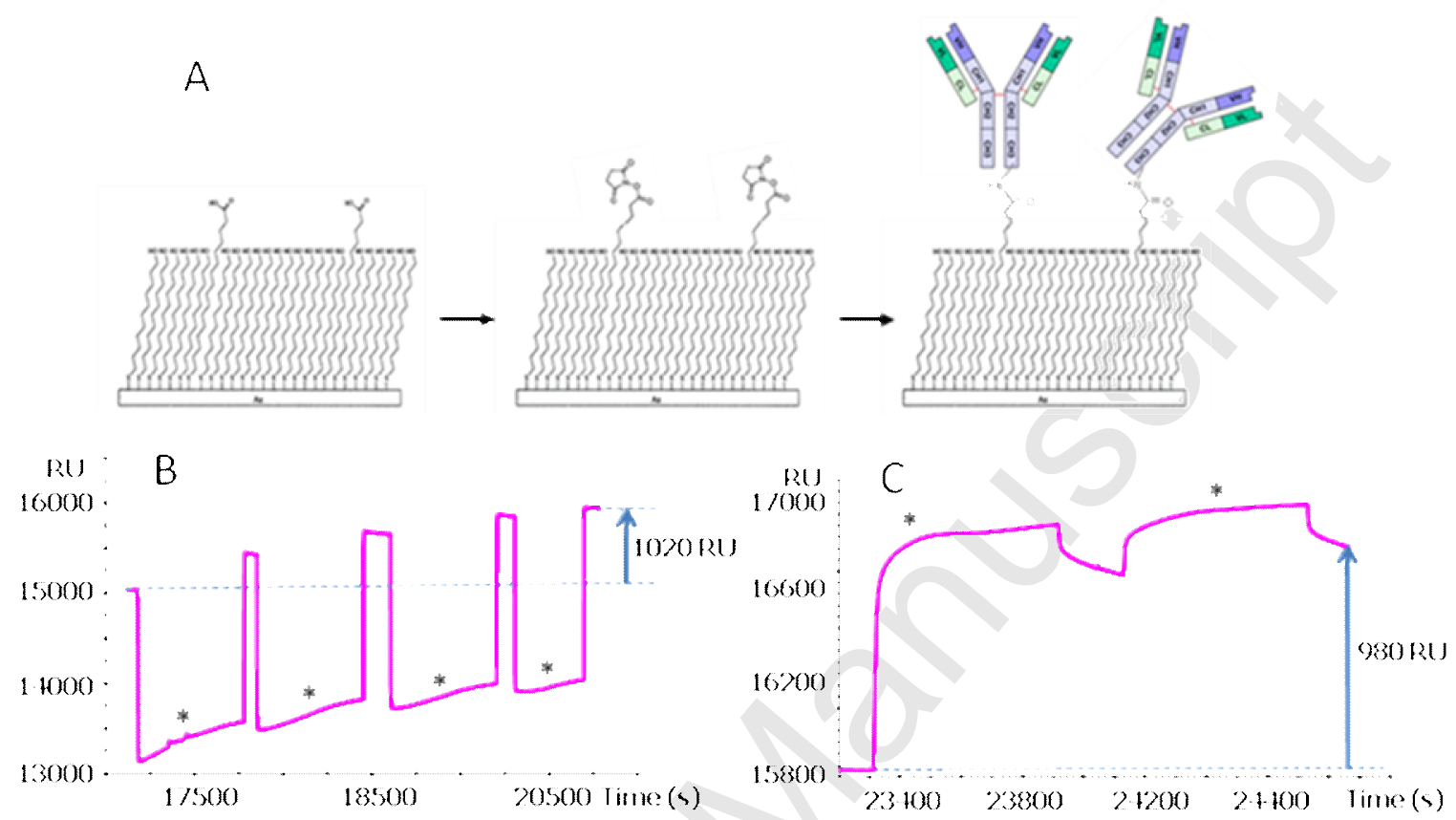
Figure 4

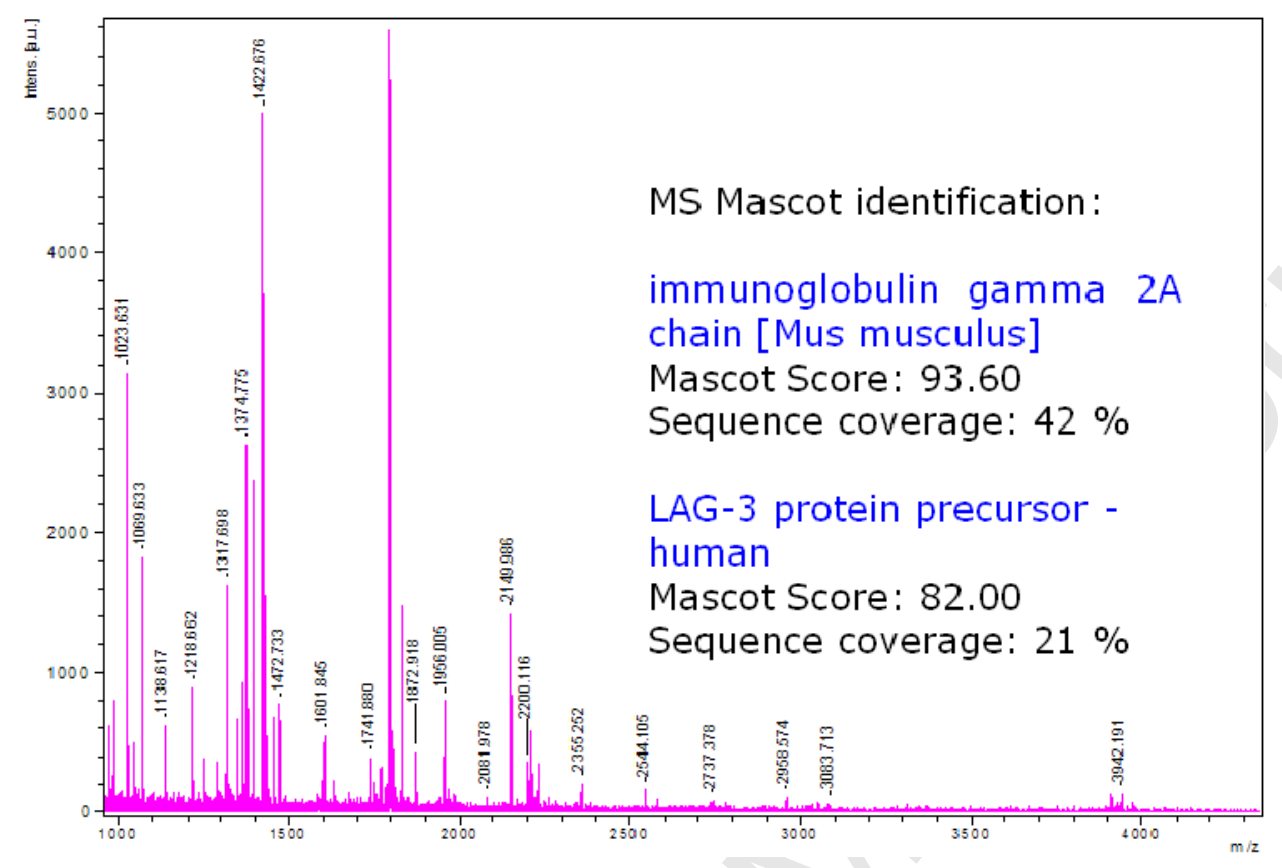


Figure 5

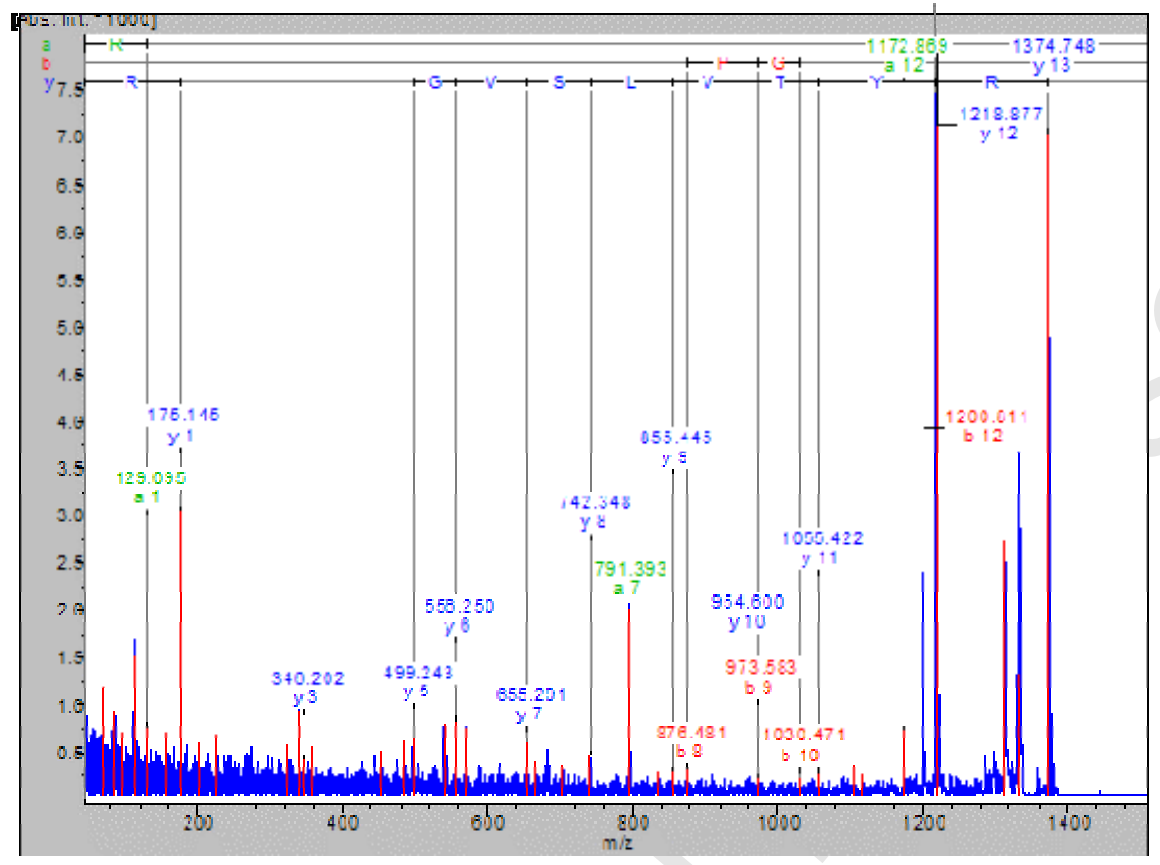

$\mathrm{m} / \mathrm{z} 1374$

MSMS Mascot identification:

LAG-3 protein - human Mascot Score: 52.94

Sequence: RYTVLSVGPGGLR 


\begin{tabular}{|c|c|c|c|c|}
\hline $\begin{array}{c}\text { Tree } \\
\text { hierarchy }\end{array}$ & Meas. $\mathrm{M} / \mathrm{z}$ & Calc. $\mathrm{MH}^{+}$ & Range & Sequence \\
\hline peak 2 & 1019.578 & 1019.578 & $234-242$ & AFKAWAVAR \\
\hline peak 3 & 1177.589 & 1177.607 & $25-34$ & EAHKSEIAHR \\
\hline peak 7 & 1266.627 & 1266.636 & $247-257$ & FPNAEFAEITK \\
\hline peak 8 & 1345.652 & 1345.697 & $299-310$ & LQACCDKPVLQK \\
\hline peak 9 & 1374.660 & 1374.603 & $287-298$ & YMCENQATISSK \\
\hline peak 11 & 1439.747 & 1439.785 & $439-452$ & APQVSTPTLVEAAR \\
\hline peak 13 & 1465.707 & 1465.780 & $422-434$ & LGEYGFQNAVLVR \\
\hline peak 14 & 1475.695 & 1475.655 & $222-233$ & MKCSSMQRFGER 1: Ox (M) \\
\hline peak 15 & 1482.824 & 1482.798 & $484-496$ & LCVLHEKTPVSEK \\
\hline peak 16 & 1508.808 & 1508.812 & $230-242$ & FGERAFKAWAVAR \\
\hline peak 18 & 1562.798 & 1562.720 & $224-236$ & CSSMQRFGERAFK 4: Ox (M) \\
\hline peak 20 & 1570.695 & 1570.699 & $104-117$ & LRDNYGELADCCAK \\
\hline peak 21 & 1609.757 & 1609.790 & $348-360$ & DVFLGTFLYEYSR \\
\hline peak 23 & 1657.821 & 1657.775 & $118-130$ & QEPERNECFLQHK \\
\hline peak 30 & 1784.799 & 1784.864 & $243-257$ & MSQRFPNAEFAEITK 1: Ox (M) \\
\hline peak 35 & 1880.020 & 1880.035 & $439-456$ & APQVSTPTLVEAARNLGR \\
\hline peak 36 & 1891.865 & 1891.897 & $585-602$ & AADKDNCFATEGPNLVAR \\
\hline peak 38 & 1940.848 & 1940.811 & $106-122$ & DNYGELADCCAKQEPER \\
\hline peak 39 & 1941.937 & 1941.993 & $29-44$ & SEIAHRFKDLGEQHFK \\
\hline peak 41 & 1960.009 & 1960.050 & $435-452$ & YTQKAPQVSTPTLVEAAR \\
\hline peak 45 & 2265.181 & 2265.267 & $439-460$ & APQVSTPTLVEAARNLGRVGTK \\
\hline peak 46 & 2446.120 & 2446.116 & $265-286$ & INKECCHGDLLECADDRAELAK \\
\hline peak 47 & 2513.232 & 2513.270 & $243-264$ & MSQRFPNAEFAEITKLATDVTK 1: Ox (M) \\
\hline
\end{tabular}

Table 1: Matched peptides from MALDI-TOF measurements of 0.7 femtomoles $/ \mathrm{mm} 2$ of adsorbed RSA on OM SAM digested with trypsin. Peptide tolerance was set at $+/-50 \mathrm{ppm}$. 


\begin{tabular}{|c|c|c|c|c|}
\hline \multicolumn{5}{|c|}{ Digest $M$ atches (Score: 93.60$)$} \\
\hline Tree hierarchy & Meas. M/z & Calc. $\mathrm{MH}+$ & Range & Sequence \\
\hline peak 1 & 984.625 & 984.584 & $92-99$ & VDKKIEPR \\
\hline peak 7 & 1140.568 & 1140.590 & $100-110$ & GPTIK PCPPCK \\
\hline peak 13 & 1365.709 & 1365.748 & $205-216$ & VNNKDLPAPIER \\
\hline peak 21 & 1596.817 & 1596.853 & $203-216$ & CK VNNKDLPAPIER \\
\hline peak 28 & 1952.874 & 1952.858 & $275-291$ & NTEPVLDSDGSYFMYSK \\
\hline peak 29 & 1956.005 & 1956.015 & $227-243$ & APQVYVLPPPEEEMTKK \\
\hline peak 30 & 1968.815 & 1968.853 & $275-291$ & NTEPVLDSDGSYFMYSK 14: Oxidation (M) \\
\hline peak 31 & 1971.928 & 1972.010 & $227-243$ & APQVYVLPPPEEEMTKK 14: Oxidation (M) \\
\hline peak 33 & 2149.986 & 2149.983 & $303-321$ & NSY SCSVV HEG LHNHHTTK \\
\hline peak 34 & 2200.116 & 2200.122 & $184-202$ & VVSALPIQHQDW M S G KEFK \\
\hline peak 35 & 2227.133 & 2227.143 & $223-242$ & GSVR APQVYVLPPPEEEMTK \\
\hline peak 37 & 2355.252 & 2355.238 & $223-243$ & GSVRAPQVYVLPPPEEEMTKK \\
\hline peak 40 & 2737.378 & 2737.379 & $02-29$ & TT APS VYPLAPVCGDTTGSSVTLGCLVK \\
\hline \multicolumn{5}{|c|}{ LAG 3 protein precursor - human gi|106885 } \\
\hline \multicolumn{5}{|c|}{ Digest $M$ atches (Score: 82.00$)$} \\
\hline Tree hierarchy & Meas. $M / z$ & Calc. $\mathrm{MH}+$ & Range & Sequence \\
\hline peak 3 & 1023.631 & 1023.606 & $111-119$ & SGRLPLQPR \\
\hline peak 6 & 1138.617 & 1138.655 & $205-214$ & NRGQGRVPVR \\
\hline peak 8 & 1218.662 & 1218.684 & $99-110$ & YTVLSVGPGGLR \\
\hline peak 11 & 1317.698 & 1317.706 & $130-140$ & GDFSLWLRPAR \\
\hline peak 14 & 1374.775 & 1374.785 & $9.8-110$ & RYT VLSVGPGGLR \\
\hline peak 15 & 1395.778 & 1395.789 & $2.78-291$ & VGLPCRLPAGVGTR \\
\hline peak 16 & 1422.676 & 1422.701 & $380-391$ & FVW S SLDTPSQR \\
\hline peak 17 & 1430.707 & 1430.731 & $367-379$ & LLCEVTPVSGQER \\
\hline peak 19 & 1472.733 & 1472.753 & $166-180$ & LGQASMTASPPGSLR \\
\hline peak 20 & 1488.688 & 1488.747 & $166-180$ & LGQASMTASPPGSLR 6: Oxidation (M) \\
\hline peak 22 & 1601.845 & 1601.866 & $128-140$ & QRGDFSLWLRPAR \\
\hline peak 25 & 1741.880 & 1741.938 & $164-180$ & LRLGQ ASM T ASPPGSLR \\
\hline peak 26 & 1757.979 & 1757.967 & $128-141$ & QRGDFSLWLRPARR \\
\hline
\end{tabular}

Table 2: Matched peptides from MALDI-TOF measurements of 6 femtomoles $/ \mathrm{mm}^{2}$ of antigen LAG-3 specifically captured with the immunochip A9H12. Digestion was performed with

trypsin. Peptide tolerance was set at $+/-50 \mathrm{ppm}$. 